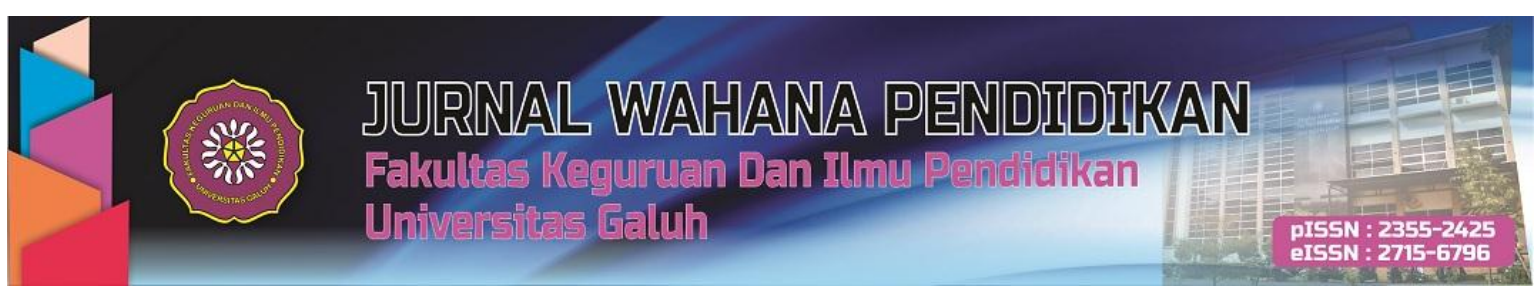

https://jurnal.unigal.ac.id/index.php/jwp

\title{
PERANAN KESATUAN AKSI MAHASISWA INDONESIA DAN KESATUAN AKSI PELAJAR INDONESIA DALAM PROSES PERALIHAN KEPEMIMPINAN NASIONAL TAHUN 1965-1968
}

\author{
Terra Erlina \\ Universitas Galuh, Jl. R. E. Martadinata No.150, Ciamis, Indonesia \\ Email: Terraerlina77@gmail.com
}

\begin{abstract}
ABSTRAK
Penelitian ini bertujuan untuk menjelaskan aksi mahasiswa indonesia dan kesatuan aksi pelajar indonesia dalam proses peralihan kepemimpinan nasional tahun 1965-1968. Perjuangan peranan aksi-aksi mahasiswa sebagai "pressure group" sangat besar. Metode yang digunakan dalam penelitian ini yaitu penelitian histori meliputi langkah-langkah sebagai berikut: (1). Heuristik (2). Kritik, (3). interpretasi (4). Historiografi. Hasil penelitian menunjukkan bahwa Supersemar dan gerakan aksi mahasiswa telah membawa kemenangan bagi Orde Baru melalui proses konstitusional terhadap penyelewengan ideologi, politik, ekonomi, sosial dan budaya.
\end{abstract}

Kata Kunci : Aksi Mahasiswa, Peralihan Kepemimpinan

\section{ABSTRACT}

This study aims to explain the actions of Indonesian students and the unity of Indonesian student action in the process of transitioning the national leadership in 1965-1968. In the struggle the role of student actions as a "pressure group" is very large. The method used in this research is historical research including the following steps: (1). Heuristics (2). Criticism, (3). interpretation (4). Historiography. The results showed that Supersemar and the student action movement had brought victory for the New Order through a constitutional process of ideological, political, economic, social and cultural distortion.

Keywords: Student Action, Leadership Transition

Erlina, T. (2020). Peranan Kesatuan Aksi Mahasiswa Indonesia Dan Kesatuan Aksi Pelajar Indonesia Dalam Proses Peralihan Kepemimpinan Nasional Tahun 1965-1968. Jurnal Wahana Pendidikan, 7(1), 95-102. 


\section{PENDAHULUAN}

Keberadaan mahasiswa sebagai warga perguruan tinggi (Civitas Akademica) tidak hanya dididik menjadi calon-calon sarjana yang menguasai ilmu pengetahuan dan teknologi tetapi perguruan tinggi diharapkan mampu menciptakan lulusan yang mampu mengembangkan ilmu bagi kemajuan masyarakat dan mampu mengembangkan nilai-nilai moral (Sarwono, 1978:49; Wijayanti, 2019). Hal itu sejalan dengan tabiat dari ilmu itu sendiri, mahasiswa memiliki kepekaan yang tinggi terhadap peristiwa-peristiwa sosial dan lebih kritis dalam melihat kepincangan-kepincangan sosial politik yang terjadi serta mempunyai kemampuan untuk melakukan perubahan-perubahan.

Sifat inilah seringkali sangat menentukan fungsi mahasiswa dalam perubahan politik maupun sosial. Peranan ini akan juga melahirkan minoritas yang sanggup membawa sikap politik mahasiswa sebagai kelompok mayoritas kearah dinamika kehidupannya dan kehidupan sosial polik serta pemerintahan (Sardiman, 2015). Kematangan para mahasiswa ini yang terwujud dalam slogan-slogan dan yel-yel di dalam demontrasi, serta issu sentral yang benar-benar mengena kepada hati nurani rakyat. Tuntunan tersebut akhirnya terkenal dengan tritura (Tiga Tuntutan Rakyat): Bubarkan PKI, Turunkan harga, dan Bubarkan Kabinet 100 mentri.

Menghadapi gelombang aksi massa mahasiswa ini dijawab oleh Soekarno dengan tuduhan bahwa gerakan mahasiswa itu ditunggangi oleh nekolim (Neokolialisme Imperialisme) serta akan mendongkel Soekarno. Kemudian Soekarno berpidato di depan Kabinet menganjurkan untuk membentuk "Barisan Soekarno" (Virdianti, 2014). Kehadiran barisan Soekarno dimanfaatkan oleh Subandrio untuk menyusun kekuatan massa, ini jelas merupakan tantangan bagi aksi mahasiswa, KAMI dilarang melakukan demontrasi diwilayah DKI Jakarta dan pada akhirnya disusul dengan surat keputusan No. 041/Kogam/1966 yang lainnya mencabut hak hidup KAMI.

Surat keputusan tersebt ditanggapi oleh KAMI dengan mengeluarkan ikrar keadilan dan kebenaran yang salah satu isinya menolak dengan tegas keputusan Presiden tersebut mengenai pembubaran KAMI. Yang paling keras mengecam adalah KAMI Bandung yang dimotori mahasiswa ITB. Menghadapi keadaan yang semakin tidak terkendali, akhirnya pada tanggal 11 Maret 1966 Presiden Soekarno mengeluarkan sutar perintah kepada Mayjen Suharto yang kita kenal dengan Supersemar. Lahirnya Supersemar akhirnya dijadikan tonggak sejarah sebagai lahirnya Orde Baru. Rumusan masalah yang sesuai dengan penjelasan diatas adalah Bagaimana peralihan kepemimpinan nasional tahun 1965-1968?

\section{METODE PENELITIAN}

Metode Historis sangat tepat digunakan dalam penelitian ini, karena meneliti tentang peristiwa yang terjadi pada masa lampau yang berkaitan dengan usaha yang dilakukan KAMI dan KAPI dalam suksesi kepemimpinan Nasional dari Orde Lama ke Orde Baru. Adapun tahapan metode historis diantaranya yaitu:

1. Heuristik

Pada tahap peneliti mencari sumber-sumber sejarah atau jejak, fakta dan data masa lampau.

2. Kritik

Selanjutnya peneliti melakukan pengujian terhadap sumber yang telah diperoleh untuk menentukan keaslian dan kevalidan sumber yang ada.

3. Interpretasi

Penulis melakukan penafsiran dan analisis terhadap data dan fakta yang sudah terkumpul. 


\section{Historiografi}

Pada tahap akhir peneliti melakukan penulisan karya ilmiah.

Sedangkan teknik pengumpulan data yang dilakukan peneliti adalah melalui studi literature atau studi kepustakaan yakni dengan mengumpulkan sumber-sumber yang sesuai baik itu buku, jurnal maupun prociding.

\section{HASIL DAN PEMBAHASAN}

\section{PERALIHAN KEPEMIMPINAN NASIONAL TAHUN 1965-1968}

\section{Lahirnya Surat Perintah 11 Maret 1966}

Mahasiswa tergabung dalam kesatuan aksi tetap berjuang menyuarakan hati nurani rakyat untuk mewujudkan tritura. Selama Tritura belum terpenuhi maka intensitas perjuangan mahasiswa akan selalu meningkat. Hal ini karena perjuangan mahasiswa telah memiliki bekal semangat yang menyala-nyala: patriotism, idealism, dan persatuan. Ini berarti bahwa mahasiswa telah menunjukkan eksistensinya, tampil dengan penuh heroism, berani sekaligus mempelopori gerakan umum perjuangan Tritura.

Tritura adalah manifestasi dari keterlibatan makasiswa Indonesia di dalam berbangsa dan bernegara. Tritura adalah wujud perjuangan mengoreksi jalannya sejarah, pembela pancila dan UUD 1945 (Robiyani, 2017). Dipandang dari isinya Tritura mengandung makna yang sangat luas. Hal ini dapat dfahami dengan menggali isinya yaitu:

Pertama, pembubaran PKI mengandung makna, tekad untuk membela, menegakkan dan mengamalkan Pancasila. Sedangkan Pancasila tidak mungkin dilaksanakan oleh PKI, sebab ideology PKI mengandung unsur-unsur yang tidak mendasar bertolak belakang dengan Pancasila. Dengan demikian PKI harus dibubarkan dari seluruh wilayah Indonesia secara yuridisformal dan lebih dari itu ialah pelarangan penyebab faham, falsafah, mentalitas dan cara serta metode politik PKI dan ormas-ormasnya yang tidak sesuai dengan Pancasila dan UUD 1945 (Labrousse, 1993). Konsekwensi logis untuk jangka panjang mengandung makna pembersihan tubuh bangsa Indonesia dari unsur-unsur yang memusuhi Pancasila. Disatu pihak juga berarti tekad untuk terus menerus menetapkan dan meresapkan ideology Nasiional Pancasila kedalam seluruh kehidupan bangsa, Negara dan masyarakat.

Kedua perombakan Kabinet Dwikora dar unsure-unsur PKI. Sebaga konsekwensi logis tersirat: (1). Pembersihan aparatur Negara dari penyelewengan-penyelewengan ideologis, sehingga terciptanya tentram di hati rakyat, (2). Pembersihan aparatur Negara dari korupsi, cara kerja yang tidak efisien serta management dengan maksud menciptakan aparatur pemerintah yang bersih dan berwibawa. Dengan demikian pemerintah harus berorientasi sepenuhnya pada Pancasila.

Tiga, tuntutan penurunan harga dicetuskannya Tritura mempunya esensi penurunan harga secara normal, dari tingkat harga kebutuhan pokok sehari-hari dan turun secara fisik harga-harga tarif.

Makna Tritura yang diuraikan diatas maka terlihat bahwa Tritura yang dicetuskan oleh makasiswa memiliki nilai yang penting didalam membimbing dan mengarahkan pertumbuhan dan perkembangan bangsa Indonesia. Reaksi KAMI dengan Trituranya merupakan symbol kebangkitan mahasiswa dalam menentang ketidakadilan dan ketidakbenaran. sekaligus merupakan manifestasi jeritan suara hati nurani rakyat.

Sidang cabinet Dwikora dimulai tanggal 11 Maret 1966, dipimpin langsung oleh presiden Soekarno. Diluar sidang, mahasiswa melakukan demonstrasi menyuarakan Tritura, menutup jalan 
menuju istana untuk menggagalkan sidan kaninet. Massa menuduh bahwa orang-orang yang duduk dalam cabinet adalah orang-orang yang terlibat dalam G 30 S/PKI.

Sidang cabinet yang tidak selesai (gagal) dan mengungsinya Presiden, menunjukkan adanya kewibawaan Presiden/pemerintah sudah semakin merosot. Kepercayaan rakyat pada presiden semakin berkurang. Mayjen Yusuf, Mayjen Basuki dan Mayjen Amir Mahmud sepakat untuk menyusul Presiden Soekarno ke Istana Bogor. Mereka khawatir akan semakin terpengaruh oleh pandangan PKI melalui Waperdam.

Sebelum berangkat ke Bogor, ketiga perwira tersebut dititipkan pesan oleh Soeharto yang isinya "Sampaikan kepada presiden bahwa saya sanggup mengatasi keadaan". Di istana Bogor, ketiga perwira tersebut menyampaikan saran-saran dan titipan pesan dari Letjen Suharto kepada Presiden Soekarno. Setelah selesai dialog maka oleh Presiden diputuskan untuk mengeluarkan surat perintah kepada mentri/Panglima Angkatan Darat Mayjen Soeharto. Oleh ketiga perwira tersebut dan ketiga Perdana Mentri serta Brigjen Subur, disusunlah surat perintah (Isharianto, 2003). Surat Perintah tersebut ditandatangani oleh Presiden dengan ucapan "Bismillahirohmanirohim", Surat Perintah tersebut akhirnya dikenal dengan nama surat perintah 11 maret (Supersemar). Adapun isi surat perintah 11 Maret 1966 itu adalah mengambil segala tindakan yang dianggap perlu untuk terjaminnya keamanan dan ketenangan serta kestabilan jalannya revolusi.

\section{Jatuhnya Pemerintahan Soekarno}

Desakan-desakan massa aksi yang berturut-turut menuntut kepada Presiden Soekarno untuk bertanggung jawab atas terjadinya G 30 S/PKI, mendorong MPRS untuk mengeluarkan nota No. 2/pimp/MPRS/1966 tertanggal 22 Oktober 1966 yang isinya meminta kepada Presiden Soekarno supaya memenuhi keputusan MPRS No. V/MPRS/1966.Perjuangan konstitusional juga dilakukan oleh massa KAPPI dengan menyampaikan memorandum kepada DPRGR tanggal 30 Nopember 1966. Isi daripada memorandum tersebut merupakan sikap daripada KAPPI. KAPPI berpendapat bahwa menurut kenyataan Soekarno adalah presiden RI yang sah, tetapi KAPPI menganggap Soekarno tetap salah, karena itu ia harus mempertanggungjawabkan terjadinya G 30 S/PKI dan kemerosotan ekonomi, kemerosotan ahlak serta kehancuran demokrasi.

Atas perkembangan situasi tersebut KAMI pusat segera mengumpulkan eksponennya se Jawa pada tanggal 9 sampai 12 Desember 1966, bertempat dikota Lembang Jawa Barat. Pertemuan konsulat-konsulat KAMI se Jawa tersebut menghasilkan suatu pernyataan atas nama kurang lebih 200.000 mahasiswa Indonesia. Isinya menuntut kepada yang berwenang sesuai dengan UUD 11945 untuk segera mengadili Soekarna (Mingguan Mahasiswa Indonesia, 18 Desember 1966).

Pernyataan sikap tentang Presiden Soekarno diikuti pula oleh Persatuan Sarjana Hukum Indonesia. Persatuan tersebut disebut IKAHI. Pada Tanggal 18 Desember 1966 IKAHI mengeluarkan "Deklarasi Keadilan dan Kebenaran" yang ditandatangani oleh Asikin Kusumaatmaja (Ketua Umum IKAHI), Mashuri, SH (Ketua Umum PERSAHI), yang isinya:

(1). Agar Presiden Soekarno dipecat dengan tidak hormat berdasarkan instruksi KOGAM no. 09/Kogam/5/1966 dan Instruksi KOTI No. 22/KOTI/1965.

(2). Demi tegaknya keadilan hukum perlu dengan segera diadakan pemeriksaan menurut hukum terhadap Presiden Soekarno.

Rangkaian pernyataan yang berturut-turut itu akhirnya mendorong kepada empat Angkatan Bersenjata Republik Indonesia untuk mengeluarkan pernyataan bersama. Pernyataan empat 
Angkatan Bersenjata tersebut mencerminkan sikap adanya keutuhan dan kekompakan dalam mengamankan dan mengawal perjuangan konstitusional serta menunjukan sikap ABRI untuk bertindak tanpa pilih bulu terhadap siapa saja yang tidak mentaati Pancasila dan UUD 1945 serta hasil-hasil sidang umum MPRS IV.

Pernyataan keempat angkatan itu, mempunyai pengaruh yang kuat terutama atas pendirian Presiden Soekarno untuk mempertahankan kekuasaannya menjadi benar-benar goyah. Hal itu terbukti dengan dikeluarkannya Surat No. 10/Pres/1967 tertanggal 10 Januari 1967 oleh Presiden Soekarno yang isinya melengkapi pidato NAWAKSARA. Surat tersebut kemudian terkenal dengan nama "Pel-Nawaksara". Isi pokok Pel Nawaksara tersebut adalah:

(1). Presiden masih meragukan keharusannya untuk memberikan pertanggungjawaban, menurut Presiden dalam UUD 1945 ataupun dalam keputusan MPRS sebelum sidang umum MPRS IV, tidak ada ketentuan bahwa Mandataris harus memberikan pertanggungjawaban atas hal-hal yang "cabang".

(2). Atas terjadinya Gestapu/PKI Presiden mengatakan/: kenapa saya yang diminta pertanggungjawaban atas terjadinya G 30 S/PKI. Tidakkah misalnya Menko/Hankam (waktu itu yang bertanggungjawab?).

Dengan Pel-Nawaksara tersebut Presiden Soekarno seolah-olah melemparkan tanggung jawabnya kepada Menko/Hankam. Dan itu berarti Soekarno merasa tidak bersalah atas terjadinya penghianatan G30S/PKI. Kemudian pimpinan MPRS member keterangan kepada Pers RRI dan TVRI, dimana Presiden masih meragukan keharusannya untuk member pertanggungjawabannya kepada MPRS sebagaimana ditentukan oleh MPRS No. XIV/MPRS/1966 yang isinya Mandataris MPRS berkewajiban memberikan pertanggungjawaban mengenai kebijaksanaan putusan-putusan MPRS.

Reaksi-reaksi keras datang dari berbagai ormas-ormas mahasiswa dan masyarakat secara luas. Ketidakpuasan itu muncul dengan sikap yang lebih radikal menentang Pel-Nawaksara. Demonstrasi mahasiswa tampil menyuarakan agar Presiden Soekarno diberhentikan dan diadili atas segala penyelewengannya. Perjuangan melalui konstitusionalpun terus dilancarkan yaitu dengan cara mendesak kepada MPRS untuk bersidang kembali.

Lembaga MPRS akan diadakan perombakan dan penambahan susunan DPRGR. suarasuara agar tokoh-tokoh KAMl diangkat menjadi anggota Dewan semakin meluas. Hal itu dimaksudkan untuk lebih memantapkan perjuangan mahasiswa duduk dalam DPRGR menimbulkan perbedaan pendapat antara pro dan kontra. Yang Pro mendukung sepenuhnya perjuangan tersebut dan yang kontra menentang duduknya mahasiswa dalam DPRGR. Sekalipun demikian akhirnya Presidium KAMI pusat pada akhirnya menerima ajakan tersebut. Hal itu dimaksudkan agar perjuangan semakin ditingkatkan dari dalam yakni dengan cara konstitusional.

Perjuangan mahasiswa kini dilakukan melalui dua jalur yaitu aksi Demonstrasi parlemen jalan raya dan perjuangan konstitusional melalui DPRGR. Melalui DPRGR perjuangan itu berhasil mengeluarkan suatu resolusi tersebut kemudian terkenal dengan nama: "Resolusi DPRGR 9 Februari" isinya adalah: Meminta kepada pimpinan MPRS selambat-lambatnya bulan Maret 1967, untuk:

(1). Memberhentikan Presiden Soekarno dari jabatan/Mandataris MPRS yang menurut DPRGR terbukti dengan nyata kesalahannya, memilih/mengangkat pejabat sesuai dengan pasal tiga ketetapan MPRS No. XVI/MPRS/1966. 
(2). Memerintahkan kepada badan kehakiman yang berwenang untuk mengadakan pengusutan, pemeriksaan dan penuntutan secara hukum.

\section{Suksesi Kepemimpinan Nasional dan Konsesus Nasional}

Kedudukan Presiden Soekarno semakin terpojok dan lemah, terutama setelah PelNawaksara ditolak oleh Sidang Badan Pekerja ke-3 MPRS tanggal 14-16 Februari 1967. Melihat perkembangan yang semakin mengancam kedudukannya, maka Soekarno mula menyadari akan kelemahan-kelemahan didalam memimpin bangsa dan Negara. oleh karena itu presiden Soekarno akhirnya mengirimkan surat kepada Letnan Jendral Soeharto yang isinya: Presiden menugaskan khusus kepada pemegang Supersemar Jendral Soeharto untuk memegang pemerintahan seharihari, Presiden tetap memegang pimpinan kenegaraan dan menentukan garis-garis besar dari pimpinan pemerintahan. Tetapi surat tersebut ditolak oleh keempat Angkataan Bersenjata Republik Indonesia (ABRI) dalam rapatnya tanggal 8 Februari 1967. Alasannya adalah isi surat tersebut masih tetap mempertahankan dualism dalam pemerintah, yang ternyata hanya jadi hambatan bagi usaha menyukseskan program Dwi Darma Catur Karya.

Akibat penolakan itu, Presiden Soekarno makin menjadi sadar bahwa pendukungpendukungnya sudah tidak mampu lagi mempertahankan atau memperkuat kedudukannya sebagai kepala Negara. oleh sebab itu Soekarno memutuskan untuk menerima konsep dari empat Panglima Angkatan (ABRI) untuk menyerahkan kekuasaan pemerintahan kepada Jendral Soeharto (Nasution $\mathrm{AH}, 1975: 16)$.

Pada tanggal 22 Februari 1967 di istana merdeka penyerahan kekuasaan pemerintahan kepada Jendral Soeharto pengemban ketetapan MPRS No. IX/1966 yang berlaku surut mulai tanggal 20 Februari 1967. Peristiwa serah terima itu disaksikan oleh segenap Menteri Kabinet Ampera dan empat Panglima Angkatan (ABRI). Dengan adanya penyerahan kekuasaan tersebut maka Orde Baru telah berhasil secara bertahap untuk mengambil alih kekuasaan dari Pemerintahan Orde Lama.

Perjuangan Konstitusionalpun terus dilancarkan terutama mengenai penyerahan kekuasaan dari presiden Soekarno kepada Letjen Soeharto. Usaha-usaha agar Mayjen Soeharto pengemban Supersemar memperoleh kekuasaan yang sah terlihat dalam sidang MPRS yang dilaksanakan pada tanggal 7-12 Maret 1967. salah satu keputusan yang penting dalam tap MPRS. No. XXXIII/1967, tentang pencabutan kekuasaan pemerintahan Negara dari Presiden Soekarno. isi dari Tap MPRS tersebut antara lain adalah:

(1) Bahwa Presiden Soekarno tidak dapat memenuhi pertanggungjawaban konstitusional.

(2) Bahwa Presiden Soekarno tidak dapat menjalankan haluan dan putusan MPRS.

(3) Melarang Presiden Soekarno melakukan kegiatan politik sampai dengan pemilihan umum yang akan datang sejak berlakunya ketetapan ini menarik kembali Mandat MPRS dari Presiden Soekarno serta segala kekuasaan pemerintahan Negara yang diatur dalam UUD 1945.

(4) Mengangkat Jendral Soeharto Pengemban Ketetapan MPRS No. IX/MPRS/1966 sebagai pejabat Presiden, sehingga terpilihnya Presiden oleh MPR hasil pemilihan umum.

(5) Penyelesaian persoalan hukum selanjutnya yang menyangkut Dr. Ir. Soekarno, dilakukan menurut ketentuan hukum, dan pelaksanaannya diserahkan kepada pejabat Presiden.

(6) Ketetapan ini mulai berlaku pada hari ditetapkan dan berlaku surut tanggal 23 Februari 1967

Setelah keputusan tersebut diambil dan diberlakukan, pada tanggal 12 Maret 1967, Ketua MPRS Jendrall Nasution di depan Sidang Pleno mengambil Sumpah dan melantik secara Islam Jendral Soeharto sebagai Pejabat Presiden Republik Insdonesia Konstitusional pertama. Dengan 
pengangkatan tersebut, maka segala kekuasaan Negara dan para pejabat presiden Jendral Soeharto.

Keputusan MPRS tersebut diatas kemudian diperkuat oleh ketetapan MPRS No. XLIV/MPRS/1968 yaitu tentang Pengangkatan Pengemban Ketetapan MPRS No. IX/MPRS/1966 sebagai Presiden Republik Indonesia. Dengan berlakunya ketetapan MPRS No. XLIV/MPRS/1968, maka Jendral Soeharto telah sah menjadi Presiden Republik Indonesia sampai dengan terpilihnya Presiden oleh MPR hasil pemilihan umum.

Berhasilnya Pengemban Supersemar dan Ketetapan MPRS No. IX/MPRS/1968 mnejadi pejabat presiden sampai dengan terpilihnya Presiden oleh MPR hasil pemilu menunjukan kemenangan yang gemilang bagi perjuangan tritura. Ini juga berarti Orde Baru berhasil mengambil alih kekuasaan dari Orde Lama, melalui perjuangan Konstitusional. Esensi dari kemenangan tersebut adalah bahwa Orde Baru berhasil meletakan dasar cita-cita perjuangan. Yakni keinginan untuk:

(1) Mewujudkan suatu pemerintahan Konstitusional.

(2) Melaksanakan Demokrasi sebagaimana termaktub dalam UUD 1945.

(3) Adanya kemampuan terorganisasi bagi pembangunan ekonomi secara pesat.

(4) adanya kelangsungan dan kontinuitas politik luar negeri kepemimpinan nasional.

Sedangkan Maergawan (1967) memperinci bahwa keberhasilan Tritura sampai dengan berakhirnya Sudang Umum Istimewa MPRS sebagai berikut:

(1) Bahwa seluruh kekuatan Orde Baru berhasil dalam membuat landasan perjuangan bersama: Pancasila, UUD 1945, dan hasil-hasil Sidang Umum IV MPRS.

(2) Bahwa rakyat Indonesia berhasil dalam mendidik dirinya untk mematuhi tata tertib konstitusional tata tertib Demokrasi Pancasila.

(3) Bahwa kita berhasil dalam mengembalikan kedaulatan di tangan rakyat (MPR).

(4) Bahwa kita berhasil dalam menghancurkan benteng terakhir Orde Lama.

(5) Bahwa kita harus terus memperjuangkan berhasilnya Dwi Dharma Catur Karya, terutama perbaikan kehidupan rakyat di bidang sandang dan pangan.

Mahasiswa yang merasa cukup puas atas perjuangannya sampai dengan duduknya Soeharto menjadi pejabat Presiden dan terpenuhinya Tritura, berpendapat perlu lebih meningkatkan perjuangan dengan mengikis habis sisa-sisa Orde Lama dan mempersiapkan segala Prasarana politik demi kelancaran Pemerintaha Orde Baru. Perkembangan baru yang dilakukan oleh pemerintah Orde Baru sebagai realisasi dari ketetapan-ketetapan MPRS yang pada pokoknya menghendaki pembaharuan di segala bidang. hal itu mendorong pula bagi organisasi KAMI untuk segera mengadakan konsolidasi atas hasil-hasil perjuangan Tritura. Konsolidasi tersebut dianggap perlu dengan segera karena isu-isu bersama satu-satu telah terealisasi. Oleh sebab itu perjuangan berikutnya dalam rangka memenuhi amanat penderiataan rakyat yang tetap teguh dalam wadah KAMI. Melihat perkembangan situasi seperti diatas, maka gagasan konsolidasi KAMI terwujud yaitu dengan menyelenggarakan RAKER (Rapat Kerja) pada bulan Juli 1967 bertempat di Ciawi Bogor. Perjuangan atau tujuan KAMI selanjutnya dalam menempuh masa depannya. Rumusan tersebut antara lain adalah:

(1) Melancarkan Pembangunan ekonomi secara pesat.

(2) Membangun suatu bangunan politik dan system Demokrasi Pancasila.

(3) Melancarkan proses madernisasi di segala bidang 
Dalam rapat kerja tersebut sudah mulai Nampak adanya perbedaan pendapat yang tajam, khususnya dalam menginterpretasi situasi dan kondisi Negara yang berkembang pada saat itu. kenyataan tersebut pada perkembangan berikutnya membawa dampak yang pada tubuh Kesatuan Aksi Mahasiswa Indonesia (KAMI) menuju kepada kelemahan dan kerapuhan.

\section{SIMPULAN}

Peranan aksi-aksi mahasiswa sebagai "pressure group" sangat besar. Dengan kata ini KAMI beserta Trituranya telah mempercepat proses lahirnya Supersemar. Supersemar dan gerakan aksi mahasiswa telah membawa kemenangan bagi Orde Baru melalui proses konstitusional terhadap penyelewengan ideologi, politik, ekonomi, sosial dan budaya.

\section{REKOMENDASI}

Peneliti selanjutnya dapat mengkaji peranan kesatuan aksi mahasiswa indonesia dan kesatuan aksi pelajar indonesia masa kini.

\section{UCAPAN TERIMAKASIH}

Peneliti mengucapkan terimakasih kepada pihak-pihak yang telah membantu dalam kegiatan penelitian yang dilakukan yaitu pihak civitas akademika Universitas Galuh terutama Program studi pendidikan sejarah.

\section{DAFTAR PUSTAKA}

Isharianto, R. (2003). Merancang Sejarah Gereja Yang Solider. Studia Philosophica et Theologica, $3(1), 45-54$.

Labrousse, P. (1993). The Second Life of Bung Karno Analysis of the Myth (1978-1981). Indonesia, (57), 175-196.

Nasution AH, (1975). Tanya Jawab Mahasiswa Taruna. Jakarta

Robiyani, A. (2017). Perjuangan Mahasiswa Angkatan 66: Tuntutan Pembubaran Partai Komunis Indonesia (Pki). Tsaqofah, 15(2), 111-134.

Sardiman, S. (2015). Menakar Posisi Sejarah Indonesia pada Kurikulum 2013. ISTORIA: Jurnal Pendidikan dan Sejarah, 11(2).

Sarwono, S. W. (1978). Perbedaan antara pemimpin dan aktivis dalam gerakan protes mahasiswa. Bulan Bintang.

Virdianti, P. (2014). Proses Penetapan Garuda Pancasila Sebagai Lambang Negara Indonesia Tahun 1949-1951. Avatara, 2(2).

Wijayanti, Y. (2019). Nilai-Nilai Moral Dalam Naskah Amanat Galunggung Untuk Pendidikan Karakter. Jurnal Wahana Pendidikan, 5(4), 94-100. 